\title{
Comparative Efficacy of Timolol and Latanoprost on Intraocular Hypertension Among Patients Attending the Ophthalmic Clinic of Irrua Specialist Teaching Hospital, Irrua, Nigeria
}

\author{
${ }^{1}$ Ovienria W. A., ${ }^{1}$ Enock M.E., ${ }^{2}$ Akhideno P. E., ${ }^{1}$ Momoh N., ${ }^{3,4}$ Akpamu U. \\ ${ }^{I}$ Department of Ophthalmology, Irrua Specialist Teaching Hospital, Irrua, Edo State, Nigeria. \\ ${ }^{2}$ Department of Internal Medicine, Irrua Specialist Teaching Hospital, Irrua, Edo State, Nigeria. \\ ${ }^{3}$ Department of Physiology, Faculty of Basic Medical Sciences, College of Medicine, Ambrose Alli University, \\ Ekpoma, Edo State, Nigeria. \\ ${ }^{4}$ Department of Health Promotion and Education, Faculty of Public Health, College of Medicine,University of \\ Ibadan, Ibadan, Nigeria
}

\begin{abstract}
Studies have acknowledged improved intraocular pressure results with topical pressure lowering drugs. However, paucity of literature exists among theNigerian population and among South South inhabitance in particular. It is the aim of this study to investigate and compare the efficacy of timolol and latanoprost among patients attending the Ophthalmic Clinic of Irrua Specialist Teaching Hospital, Irrua, Edo State, Nigeria.In a bid to achieve this objective, arandomized control trial was conducted from January 2014 to December 2014 involving patients with ocular hypertension. Patients were enrolled over a period of 12 weeks and followed up in 8 clinic visits over a 30 week period.A total of 104 patients completed the study (52 in timolol group and 52 in latanoprost group). The mean baseline intraocular pressures were $24.52 \mathrm{mmHg}$ in timolol group and $26.71 \mathrm{mmHg}$ in latanoprost group. Both drugs showed intraocular pressure (IOP)reducing potentials with mean percentage reduction of $34.14 \%(-8.37)$ and $40.02 \%(-10.69)$ respectively at the end of the study. Based on the results of this study, latanoprostprovides better IOP lowering effect among inhabitance around Irruaand environs.
\end{abstract}

Keywords: timolol, latanoprost, intraocular hypertension,

\section{Introduction}

Glaucoma has been defined as eye disorder where anincrease in intra-ocular pressure exist and leading to progressive damage to the optic nerveand subsequently loss of sight [1]. Although glaucoma is reported to be a leading cause of irreversible blindness throughout the world, worrisome, is the reported disproportionate effectamongstthe black race, coupledwith greater diagnosis, treatments and management challenges in black population compared to whites [2-6].

The increase in intraocular pressure has been identified as the only modifiable risk factor for the development and progression of glaucoma [7,8]. Treatment aim at intraocular pressure control therefore remains the cornerstone in glaucoma management because of its multiple risk factors, and modulating IOP is a proven strategy in reducing the risks [9]. While drugs have been effective and have played frontline role in IOP management, beta-blockersare the leading medicines in use and have shown their potentials in reducing the rate of aqueous humour production (10-12]). On the other hand,IOP reducing potentials have also been reported for prostaglandin analogues too[13-16]. Various studies have demonstrated the efficacy and safety of the common topical beta adrenergic antagonists and prostaglandin analogues in reducing $1 \mathrm{OP}$, however, they are not as effective in Africans as they are in Caucasians [17-21]. The implication is that there is variation in the IOP response of these drugs. However, these studies were conducted outside Nigeria and are short term in duration and majority are long time ago.

Interestingly, reports showed that topical pressure lowering drugs hasremained the most popular, convenient and effective mode of treatment, prevention of progression and reduction of glaucoma blindness [7,8].Studies of these tropical IOP lowering drugs are limited among Nigerian population and the inhabitance of South-South geopolitical zone of Nigeria in particular. Hence, this study is aimed at investigating and comparing the efficacy of timolol and latanoprost mono-therapy among ocular hypertensive patients attending the Ophthalmic Clinic of Irrua Specialist Teaching Hospital, Irrua, Edo State, Nigeria.Considering the reported variation in drug response between different populations, the finding of this study willpredict the response of glaucoma patients in south-south Nigeria and give a comparative overview with other population. 


\section{Materials and Methods}

2.1Drug of study:Timolol is a systemic beta-blockers acting as ocular hypotensive by decreasing aqueous secretion. It is the most used topical anti-glaucoma medication, highly available, affordable and with history of relatively good compliance as it is almost devoid of ocular side effects.

Latanoprost is a prostaglandin analogue and act by lowering IOP by increasing uveoscleral aqueous outflow. It is relatively a new class of anti-glaucoma drug with minimal systemic side effects but is expensive especially with reference to economic status of Nigerian inhabitance.

2.2 Methods:The study was a randomized control trial study conducted in the Ophthalmic Clinic ofIrruaSpecialist Teaching Hospital, Irrua, Edo State, South-South Nigeria. The study was conducted between January and December 2014.

2.3 Inclusion criteria: Ages between 10 and 80 years, both sexes, no inflammation or rubeotic glaucoma, not allergic to either of the medications, no noticeable or documented side effect to the drug of study. However, patients who are ages $<10$ or $>80 \mathrm{yrs}$, IOP $<21$ or $>50 \mathrm{mmHg}$, any form of surgical intervention, known allergies, requiring other IOP lowering modalities, existing infection or inflammation were excluded. In addition, patients who missed more than 2 clinic visits were also excluded.

2.4 Sample collection: Once a patient was identified as suitable, the study was explained to the patient and consent to be included in the study obtained.The study was explained to the patients and they were told they can decline and decide to be excluded from the study at any point in time withoutconsequence on the services they received from the clinic.

Before commencement of therapy, patients' initial IOP were measured using Goldmanns' applanation tonometer and recorded. This valueserved as the control value (based line value). Group A was placed on timololmaleate ophthalmic solution $(0.5 \%)$ applied one drop into the lower fornix of each eye at 12-hourly interval. Group B was on latanoprost ophthalmic solution $(0.005 \%)$ applied onedrop intothelower fornix of each eye once daily (in the evenings).Patients were enrolled over a period of 12 weeks in the regular clinic setting and visited during the morning $(8.30 \mathrm{am}$ to $11.30 \mathrm{am})$, afternoon $(1.00 \mathrm{pm}$ to $2.30 \mathrm{pm})$ and evening $(3.00 \mathrm{pm}$ to $4.30 \mathrm{pm})$ session. Patients for the study were followed-up in 8 clinic visits over a 30 week period. During these periods, their IOP were measured on a two week basis between the hours of 9.00am and 11.00am to take into consideration the diurnal variations of IOP.IOP was measured and recorded during each clinic visit.

2.5Analysis:SPSS (16.0 Version) was used for data entry and analysis. The descriptive statistics conducted and presented in suitable table.

\section{Results}

Table 1 shows and compares IOP reducing potentials of timolol and latanoprost among intraocular hypertensive patients attending Ophthalmic Clinic of Irrua Specialist Teaching Hospital, Irrua. The results showed high mean base line IOP in groupsA $(24.52 \mathrm{mmHg})$ and B $(26.71 \mathrm{mmHg})$. Although it was higher in group B compared to group A, however, there was no significant difference in IOP between the two groups. It was also observed that both drugs have IOP reducing capacity. However, latanoprost was more potent compared to tomolol. At the end of the study, latanoprost presented a $40.02 \%$ reduction in IOP while tomolol presented a $34.14 \%$ reduction. At the end of the study, there was a $10.69 \mathrm{mmHg}$ mean reduction in baseline value of IOP in the latanoprost treated group. The timolol treated group presented an $8.37 \mathrm{mmHg}$ mean reduction in IOP compared to entry IOP.The greatest impact on IOP reduction capacity by the both drugs was observed at the second week post commencement of treatments. Specifically, timolol presented $3.54 \mathrm{mmHg}$ reduction at the end of the second week while latanoprost presented $5.11 \mathrm{mmHg}$ mean reduction. These mean reducing capacity became milderat $6^{\text {th }}$ week, $10^{\text {th }}$ week through $30^{\text {th }}$ week post treatment which presented the weakest reduction.

Table 1: Comparative IOPReducing Potentials ofTimololandLatanoprostAmongtheOcular Hypertensive Patients

\begin{tabular}{|l|l|l|l|l|l|l|}
\hline \multirow{2}{*}{$\begin{array}{l}\text { Intraocular } \\
(\mathrm{mmHg})\end{array}$} & \multicolumn{4}{|l|}{ TIMOLOL } & \multicolumn{3}{l|}{ LATANOPROST } \\
\cline { 2 - 7 } & $\mathrm{N}$ & Mean & Mean Reduction & $\mathrm{N}$ & Mean & Mean Reduction \\
\hline Entry & 56 & 24.52 & & 52 & 26.71 & \\
\hline 2 weeks & 56 & 20.98 & 3.54 & 52 & 21.60 & 5.11 \\
\hline 6weeks & 56 & 18.48 & 2.50 & 52 & 19.92 & 1.68 \\
\hline 10 weeks & 54 & 17.96 & 0.52 & 52 & 18.35 & 1.57 \\
\hline 14 weeks & 56 & 17.64 & 0.32 & 52 & 17.73 & 0.62 \\
\hline 18 weeks & 52 & 16.77 & 0.87 & 52 & 16.88 & 0.85 \\
\hline 2 weeks & 56 & 16.73 & 0.04 & 50 & 16.70 & 0.18 \\
\hline 26weeks & 56 & 16.36 & 0.37 & 52 & 16.08 & 0.62 \\
\hline
\end{tabular}




\begin{tabular}{|l|l|l|l|l|l|l|}
\hline 30weeks & 52 & 16.15 & 0.21 & 52 & 16.02 & 0.06 \\
\hline \% reduction & & $(34.14 \%)$ & 8.37 & & $(40.02 \%)$ & 10.69 \\
\hline
\end{tabular}

\section{Discussion}

Our results showed that timolol and latanoprost have IOP reducing potentials in Nigerian patients inhabiting the South-South geopolitical zone. Our study also indicates that latanoprost is more potent than timolol. In accordance with our finding, other studies had reported timololto have less IOP lowering impactthan Latanoprost in black patients [22-24].

We also observed a negative correlation in IOP reducing potency by both drugs with time. The greatest IOP reducing impact was observed at $2^{\text {nd }}$ week post treatment and this was observed to diminishprogressively with time. Similar observations have been reported by several studies. For example, it was reported that the maximum IOP reducing effect of timolol is peaked at 2 hours after instillation and lasts for 24 hours by Zimmerman and Herbert[25]. Another study reported Timolol to be effective after many months of therapy but a tendency for slow riseof IOPhas been observed and was termed"long termdrift"[26].

We observed a $-8.37 \mathrm{mmHg}(34.14 \%)$ reducing effect for timolol which is huge compared to base line IOP. In contract to our finding, a study among healthy Nigerian population by Olateju and Ajayi[27] have reported a slight IOP lowering effect of $-2.33 \mathrm{mmHg}$. The difference between this study and our finding may be due to the state of the participants. While we observed timolol effect in intraocular hypertensive patients, the study were $2.33 \mathrm{mmHg}$ reduction was reported observed normal volunteers; who are not likely to be in need of the drug.

For latanoprost, we reported a $-10.69 \mathrm{mmHg}$ reduction at the end of the study. In line with our findings, other studies have reported similar IOP reduction potentials by latanoprost. Specifically, some of these studies have reported IOP reductions of $18-21.4 \%$ after shorter follow up periods[14-16]. A long term study however reported reduction of $20 \%$ to $30 \%$ by latanoprost in patients attending the glaucoma clinic, Norfolk and Norwich University Hospital [28].

Considering the percentage reduction in IOP (34.14\% for timolol and $40.02 \%$ for latanoprost), it can be said that both drugs are effective for management of glaucoma patients. This assertion is based on the fact that a $30 \%$ reduction in intraocular pressure (IOP) canslow the rate of progressive visual field loss [29, 30]. The 30\% reduction in IOP advocated by the CNTGS Group (1998a,b) was achieved in this study. Thus, indicating that timolol and latanoprost are effective forthe management of glaucoma in this study area and environ.

Conclusively, we observed that timolol and latanoprost have IOP reducing potentials. However, the impact produced by latanoprost was well sustainedcompared with that of timolol. These findings are found to be clinically important and might have a relative advantage in glaucoma patients, who need to have a wellsustained reduction in IOP for inhabitance in the study area and environ.

\section{References}

[1]. Regnault, A., Viala-Danten, M., Gilet, H. and Berdeaux, G. Scoring and psychometric properties of the eye drop satisfaction questionnaire (EDSQ), an instrument to assess satisfaction and compliance with glaucoma treatment. BMC Ophthalmol.; 10:1, 2010 .

[2]. Wadhwa, S.D. and Higginbotham, E.J. Ethnic Differences in Glaucoma: Prevalence, Management and outcome. Curr. Opin. Ophthal.; 16, 2005, 101-106.

[3]. Girkin, C.A. POAG in African Americans. Int. Ophthalmol. Clin.; 44: 2004, 43-60.

[4]. Racette, L., Wilson, M.R., Zangwill, L.M. et al. POAG in Blacks: A review. Surv. Ophthalmol.; 48: 2003, 295-313.

[5]. Sommer, A., Tielsch, J.M., Katzm J., et al. Racial differences in the cause-specific prevalence of blindness in east Baltimore. N. Engl. J. Med.; 325: 1991, 1412-7.

[6]. Tielsch, J.M., et al. Racial variation in the prevalence of POAG: The Baltimore eye Survey. JAMA; 266: 1991, $369-74$.

[7]. Kass, M.A., Heuer, D.K., Higginbotham, E.J., et al. The Ocular Hypertension Treatment Study: a randomized trial determines that topical ocular hypotensive medication delays or prevents the onset of primary open-angle glaucoma. Arch. Ophthalmol.; 120: 2002, 701-713.

[8]. Heijl, A., Leske, M.C., Bengtsson, B., et al. Reduction of intraocular pressure and glaucoma progression: results from the Early Manifest Glaucoma Trial. Arch. Ophthalmol.; 120: 2002, 1268-1279.

[9]. Olali, C., Malietzis, G., Ahmed, S., Samaila, E. and Gupta, M. Real-life esperence study of the safty and efficacy of travoprost 0.004\%/timoptol $0.50 \%$ fixed combination ophthalmic solution in intraocular pressure control. Nig. J. Clin. Pract.; 14 (1): 2011 , 29 33.

[10]. LeBlance, R.P., Saheb, N.E. and Krip, G. Timolol: long-term Canadian multicenter study. Can. J. Ophthalmol.; 130: 2000, 429-440

[11]. Coakes, R.L. and Brubaker, R.F. The mechanism of timolol in lowering intraocular pressure. In the normal eye. Arch. Ophthalmol.; 96: 1978, 2045-2048.

[12]. Zimmerman, T.J. and Kaufman, H.E. Timolol: a beta adrenergic blocking agent for the treatment of glaucoma. Arch. Ophthalmol.; 95: 1977, 601-4.

[13]. Tamada, Y., Taniguchi, T., Murase, H., et al. Intraocular pressure-lowering efficacy of latanoprost in patients with normal-tension glaucoma or primary open-angle glaucoma. J. Ocul. Pharmacol. Ther.; 17: 2001, 19-25.

[14]. McKibbin, M. and Menage, M.J. The effect of once-daily latanoprost on intraocular pressure and pulsatile ocular blood flow in normal tension glaucoma. Eye; 13(Pt 1): 1999, 31-4.

[15]. Greve, E.L., Rulo, A.H., Drance, S.M., et al. Reduced intraocular pressure and increased ocular perfusion pressure in normal tension glaucoma: a review of short-term studies with three dose regimens of latanoprost treatment. Surv. Ophthalmol.; 41(Suppl 2): 1997, S89-92. 
[16]. Rulo, A.H., Greve, E.L., Geijssen, H.C., et al. Reduction of intraocular pressure with treatment of latanoprost once daily in patients with normal-pressure glaucoma. Ophthalmology; 103: 1996, 1276-82.

[17]. Venter, C.P. and Joubert, P.H. Ethnic differences in response to beta 1-adrenoceptor blockade by propranolol. J. Cardiovasc. PharmacoI.; 6: 1984, 341-4.

[18]. Salako, L.A., Falase, A.O. and Aderounmu, A.F. Placebo-controlled, double-blind clinical trial of alprenolol in African hypertensive patients. Curr. Med. Res. Opin.; 6: 1979, 358-63.

[19]. Katz, M., Hubband, W.A.,Getson, A.J. and Goulds, A.L. Intraocular pressure decrease in normal volunteers following timolol ophthalmic solution. Invest. Ophthalmol.; 15: 1976, 489.

[20]. Seedat, Y.K. and Reddy, J. Propranolol in South African non-white hypertensive patients. South Afr. Med. J.; 45: 1971, 284-5

[21]. Humphreys, G.S. and Delum, D.G. Ineffectiveness of propranolol in hypertensive Jamaicans. BMJ; 2: 1968, 601-3.

[22]. Netland, P.A., Robertson, S.M., Sullivan, E.K., Silverm, L., Bergamini, M.V., Krueger, S., Weiner, A.L. and Davis, A.A. Travoprost Study Groups. Response to travoprost in black and nonblack patients with open-angle glaucoma or ocular hypertension. Adv. Ther.; 20(3), 2003, 149-63.

[23]. Halpern, M.T., Covert, D.W. and Robin, A.L. Projected impact of travoprost versus both timolol and latanoprost on visual fi elddeficit progression and costs among black glaucoma subjects. Trans. Am. Ophthalmol. Soc.; 100: 2002, 109.-118.

[24]. Hedman, K. and Larsson, L.I. The effect of latanoprost compared with timolol in African-American, Asian, Caucasian, and Mexican open-angle glaucoma or ocular hypertensive patients. Surv. Ophthalmol.; 47 Suppl 1, 2002, S77-89.

[25]. Zimmerman, J.J. and Herbert, K.E. Timolol. Arch. Opthalmol.; 95: 1997, 601-7.

[26]. Boger, W.P. Timolol-Short-term escape and long term drift. Am. J. Ophthalmol.; 11(1): 1979, 1239 -42.

[27]. Olateju, S.O. and Ajayi, A,A. The lack of efficacy of topical beta-blockers, timolol and betaxolol on intraocular pressure in Nigerian healthy volunteers. Eye; 13: 1999, 758-763.

[28]. Ang, A., Reddy, M.A., Shepstone, L. and Broadway, D.C. Long term effect of latanoprost on intraocular pressure in normal tension glaucoma. Br. J. Ophthalmol.; 88: 2004, 630-634.

[29]. Collaborative Normal-Tension Glaucoma Study Group. Comparison of glaucomatous progression between untreated patients with normal-tension glaucoma and patients with therapeutically reduced intraocular pressures. Am. J. Ophthalmol.; 126: 1998a, 487-97.

[30]. Collaborative Normal-Tension Glaucoma Study Group. The effectiveness of intraocular pressure reduction in the treatment of normal-tension glaucoma. Am. J. Ophthalmol.; 126: 1998b, 498-505. 